\title{
MASTER
}

UCRL- 87391

PREPRINT

CONF-820878--2

\section{An Investigation of Structural Changes in \\ Residential Electricity Demand}

\section{NOTICE}

Wen S. Chern

Howarth E. Bouis

\section{PORTIONS OF THIS REPORT ARE ILLEGIBLE. It}

has been reproduced from the best available copy to permit the broadest possible availability.

This paper was prepared for submittal to American Statistical Association Proceedings

Cincinnati, Ohio August 16-18, 1982

September 23, 1982

This is a preprint of a paper intended for publication in a journal or proceedings. Since changes may be made before publication, this preprint is made available with the understanding that it will not be cited or reproduced without the permission of the author. 


\section{DISCLAIMER}

This report was prepared as an account of work sponsored by an agency of the United States Government. Neither the United States Government nor any agency Thereof, nor any of their employees, makes any warranty, express or implied, or assumes any legal liability or responsibility for the accuracy, completeness, or usefulness of any information, apparatus, product, or process disclosed, or represents that its use would not infringe privately owned rights. Reference herein to any specific commercial product, process, or service by trade name, trademark, manufacturer, or otherwise does not necessarily constitute or imply its endorsement, recommendation, or favoring by the United States Government or any agency thereof. The views and opinions of authors expressed herein do not necessarily state or reflect those of the United States Government or any agency thereof. 


\section{DISCLAIMER}

Portions of this document may be illegible in electronic image products. Images are produced from the best available original document. 


\section{UCRL --87391 \\ DE83 001615 \\ I. INTRODUCTION}

This report was prepared as an account of work sponsored by an agency of the United States Governmen Neither the United States Government nor any agency thereot, nor any of their employees, makes any warraniy, express or implied, or assumes any legal liability of responsibility for the accuracy, completeness, or usefulness of any iniormation, epparatus, product. or process disclosed, or

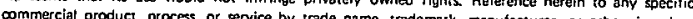
not necesserily constitute of imply is endore name, rrodemask, manufacturer, or otherwise, does Siates Government or any apency thereof. The viens, recommendation, or lavoring by the United

Price and income elasticities of residential electricity demand are essential for projecting future electricity demand growth and for effectively managing various energy pricing and conservation policies, tasks made more difficult by a wide range of estimates. For example, among the studies recently compiled and reviewed by Bohi [2], the estimated short-run price elasticities for residential electricity demand range from -0.03 to -0.54 while the long-run elasticity estimates range from -0.44 to -2.10 . For income elasticities, the short-run estimates range from 0.02 to 2.0 with the long-run estimates ranging from 0.12 to 2.20. Other comparisons are also available in Barnes et al. [1] and Taylor [11].

In investigating the stability of energy demand parameters, the following questions often arise: (1) What factors cause changes in price, income, and other demand elasticities? (2) Why do elasticity estimates vary across regions? 3) Should the elasticities estimated for the period before the oil embargo be used for forcasting demand growth for the post embargo period?

The purpose of this study is to investigate the stability of aggregate national electricity demand coefficients over time. The hypothesis is maintained that the aggregate residential demand is the sum of various end-use demand components. Since the end-use composition changes over time, the demand relationship may change as well. Since the end-use composition differs among regions, the results obtained from this study can be used for making inferences about regional differences in electricity demand relationships. There are two additional sources for a possible structural change. One-is that consumers may react diffently to declining and rising prices, secondly, the impact of the 1973 oil embargo may have shifted demand preferences. This study will show that changes in the end-use demand components have had a far greater affect on demand structure than the latter two influences.

Numerous varying-parameter models have recently been developed for testing the constancy of regression parameters over time. ${ }^{1}$. However, because of the complexity of the model structure used in this study, we chose to use the "moving regression" method proposed by Brown et al. [3] and the conventional method of partitioning sample periods with a priori information.

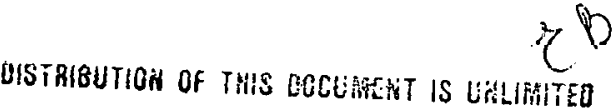


In the following section, the electricity demand model used for this study will be presented. The statistical results using the moving regression and other sample period partition methods will then be presented. The discussion of these results will focus on how and why various estimated elasticities change over time. The paper ends with some concluding remarks.

\section{AN ELECTRICITY DEMAND MOOEL}

The model used in this study follows the same specification previously used by Chern et a]. [4,5]. It is essentially a partial adjustment model in which aggregate residential demand for electricity is expressed as a function of the lagged demand and other demand determinants. Specifically, the following residential demand equation is specified:

$$
\begin{aligned}
\ln _{i t} & =\beta_{0}+\beta_{i} \ln E_{i, t-1}+\beta_{2} \ln P_{i t}+\beta_{3} \ln P C I_{i t} \\
& +\beta_{4} \operatorname{lnCr_{it}}+\beta_{5} \ln P_{i t} P_{i t}+\beta_{6} \ln H D D_{i t} \\
& +\beta_{7} \operatorname{lnCDD_{it}}+\beta_{0} \ln P_{i t}+\sum_{k=9}^{59} \beta_{k} D_{k}+u_{i t}
\end{aligned}
$$

$$
\text { where } \quad \begin{array}{ll}
i & =\text { State }(i=1, \ldots, 48), \\
t & =\text { Year }(t=1955, \ldots, 1978) \\
E & =\text { Electricity sales in the residential sector, } \\
P E & =\text { Average electricity price in the residential sector, } \\
P C I & =\text { Per capita personal income, } \\
C R & =\text { Number of residential electricity customers, } \\
P O P C R & =\text { Household size measured by dividing population by the } \\
& \text { number of residental customers, } \\
C O D & =\text { Heating degrees days, } \\
C O O & \text { Cooling degree days, } \\
P G & =\text { Average residential natural gas price, } \\
O & =\text { Dummy variables, } \\
\mu & =\text { Disturbance term. }
\end{array}
$$


The dummy variables include 47 state dummies and three dummies to account for the impacts of reclassification of residential customers which occured for several years in Wyoming, New Mexico, and Missisippi. All prices and income variables are deflated by a state-level cost-of-living index. The disturbance term is assumed to have the usual distributional properties.

It is by now well known that the use of average electricity price causes a simultaneity problem under the declining block rate structure. One remedy for this problem is to specify a price equation and estimate it simultaneously with the demand equation. We adopt the same framework used by Chern et al. [4] in which residential average price is assumed to be a function of the average cost of generation, distribution, and transmission, the number of residential customers, and other relevant dummy variables. The entire model consists of six structural equations. One demand and one price equation is specified for each of the residential, commercial, and industrial sectors. In order to avoid the impacts of a possible misspecification of the price equation, we use two-stage least squares (2SLS) to estimate each equation separately. Since the focus of this paper is on residential electricity demand, the other structural equations are not presented.

\section{MOVING REGRESSIONS}

The basic model in Eq. (1) can be rewritten in a compact form as:

$$
Y_{i t}=x_{i t} \beta_{t}+\mu_{i t,} i=1, \ldots, I ; t=1, \ldots, T
$$

The column vector of parameters, ${ }^{B} t$, is written with the subscript $t$ to indicate that it may vary with time. It is assumed the error terms, $\mu_{i t}$, are independently and normally distributed with means zero and variances $\sigma_{t}^{2}, t=$ $1, \ldots, T$. The hypothesis of constancy over time, which is denoted by $H_{0}$, is

$$
\begin{gathered}
\beta_{1}=\beta_{2}=\cdots=\beta_{T}=\beta \\
\sigma_{1}{ }^{2}=\sigma_{2}{ }^{2}=\cdots=\sigma_{T}^{2}=\sigma^{2}
\end{gathered}
$$


TAGLE 1. 2SLS Results of the 10-Years Muving keyression and the 1955-73 kegressiond

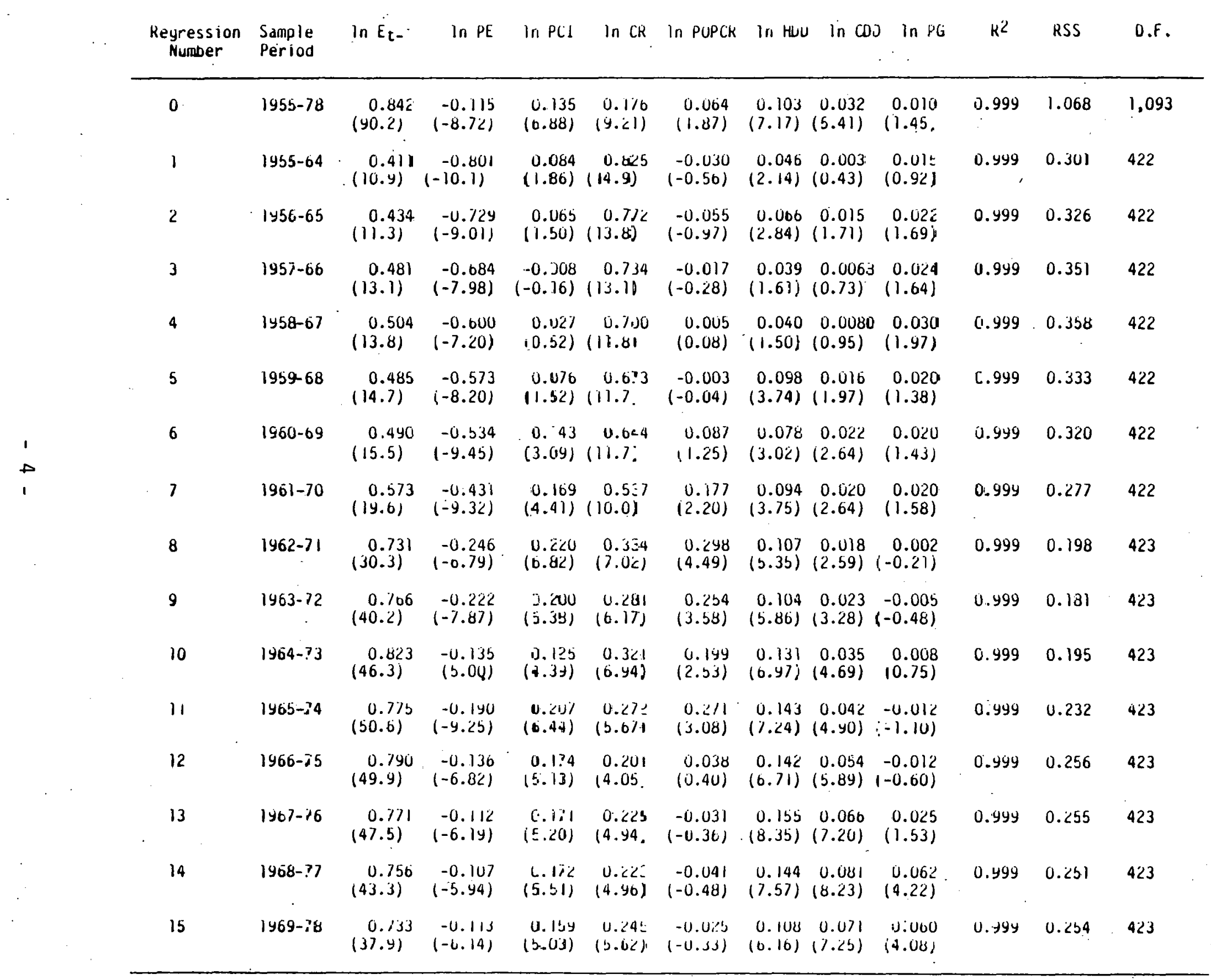

a. The figures in parentheses are estimated asyntulic t-ralius; KSS is the estimated resicual sum of

squares; 0 . F. is aegrees of freedom. Estinated curislant teril dila state duiniles are nit presented here. 
It is noted that the cross-sectional effects are treated as fixed effects captured by the state dummy variables rather than as random effects as in the variance components model.

Brown et al. [3] suggested that a useful way of investigating the time variation of $\beta_{t}$ is to fit the regression on a short segment of $n$ successive observations and to move this segment along the series. The graphs of the resulting coefficients against time provide further evidence of departures from constancy. In addition, the estimated residual variance may be computed and plotted to investigate the constancy of $\sigma^{2}$. There have been few practical applications of the "moving regression" method probably because most empirical studies lack the long sample period necessary for this kind of exercise. However, as will be shown later, this approach turns out to be very useful in detecting the structural changes in our study. We are, of course, fortunate to have adequate numbers of observations, in part, by pooling state-level data.

Data used for this analysis are annual observations for 48 states from 1955 to 1978. A segment of 10 years is chosen for conducting the moving regression. Although the choice of 10 years is purely a matter of convenience, the results for a 5-years interval show very similar patterns of changes in the estimated coefficients.

With 24 years of time-series, 15 successive regression runs can be made by moving the "window" over a 10-year interval. For each run, Eq. (1) is estimated by 2SLS using a total of 480 observations from 48 states. These regression results are summarized in Table 1. For comparison, the results from using the entire sample period 1955-1978 are also presented. Note that the degrees of freedom vary slightly among those runs because, in some cases, one or two of the three reclassification dummies has to be dropped as a result of having either al, zero or all one values in the time period under estimation.

A comparison of the results for the successive regression runs shows a strikingly consistent pattern of changes for most of the structural variables. Interpretation of these changes will be presented in the following section. Despite the magnitude of changes in the estimated coefficients, it is necessary to ask whether these changes are statistically significant. 
Brown et a1. [3] suggested a significance test for constancy which they termed the homogeneity test. This test is derived from the regression results on non-overlapping time segments, using analysis of variance. Specifically, the non-overlapping time segments for a moving regression of length $n$ are $(1, n)$, $((n+1), 2 n), \ldots,((P-1) n+1, T)$, where $P$ is the integral part of $T / n$. The homogeneity test statistic can be constructed as the following variance ratio:

$$
\frac{(T-k p)\{[S(1, T)-[S(1, n)+S(n+1,2 n)+\ldots+S(P n-n+1, T)]\}}{(K p-k)[S(1, n)+S(n+1,2 n)+\ldots+S(P n-n+1, T)]}
$$

Where $S(r, s)$ is the residual sum of squares from the regression calculated from observations $t-r$ to s inclusive. This is equivalent to the usual "between groups over within groups" ratio of mean squares. Under $H_{0}$, it is distributed as $F(k p-k, T-k p)$. In this study, $T=24, n=10$, and thus, $p=2$. We have only two non-overlapping time segments for computing the test statistic. However, we have five pairs of these segments. For computing the test statistics, the model was also estimated for a 20 year interval for the five periods (1955-74, 1956-75, 1957-76, 1958-77, and 1959-78) in order to obtain the residual sum of squares. Therefore, instead of using $T=24$, we use $T=20$ since only two periods are available for each pair. ${ }^{2}$ This test is identical to the Chow test commonly known in the econometric literature. The results of these computations are presented in Table 2. With the critical value of $F(56$, $845)=1.47$ at the 0.01 significance level, the results in Table 2 clearly show that the hypothesis $H_{0}$ is rejected in all cases. There are substantial structural changes in electricity demand over time.

\section{INTERPRETATION OF STRUCTURAL CHANGES OVER TIME}

In order to explain the pattern of changes in the estimated electricity demand relationship presented in Table 1 , it is necessary to analyze these charlyes in detail tor the estimated structural coefficients. Due to the space limitation, only three structural variables are analyzed here. 
Table 2. Significance of Structural Changes Over Time

\begin{tabular}{|c|c|c|}
\hline $\begin{array}{l}\text { Pair of } \\
\text { Regression }\end{array}$ & $\begin{array}{l}\text { Sample } \\
\text { Period }\end{array}$ & Asymptotic F-statistic ${ }^{a}$ \\
\hline $1,11$. & $\begin{array}{c}1955-64 \\
\text { VS } \\
1965-74\end{array}$ & 10.19 \\
\hline 2,12 & $\begin{array}{c}1956-65 \\
\text { VS } \\
1966-75\end{array}$ & 8.50 \\
\hline 3,13 & $\begin{array}{c}1957-66 \\
\text { vs } \\
1967-76\end{array}$ & 8.42 \\
\hline 4,14 & $\begin{array}{c}1958-67 \\
\text { vs } \\
1968-77\end{array}$ & 8.33 \\
\hline 5,15 & $\begin{array}{c}1959-68 \\
\text { vs } \\
1969-78\end{array}$ & 8.15 \\
\hline
\end{tabular}

a. These F-statistics a 11 have the degrees of freedom of 56 and 845 , respectively. 
Figure 1 shows the estimated coefficients of the 1 agged dependent variable, $\beta_{1}$ in Equation (1), from the 15 successive regression runs. The trend shows a steady increase overtime until the last 4 runs where the curve becomes flat. In our model, $1-\beta_{1}$, is the coefficient of adjustment which measures how fast the response to exogenous changes takes place. The larger the coefficient estimate, $\beta_{1}$, the slower the adjustment takes place. Thus, the results in Table 1 and Figure 1 show that for earlier sample periods, the speed of adjustment tends to be higher than that for later sample periods.

In a partial adjustment model for energy demand, the fundamental dynamic behavior is explained by changes in durable stock. For a more durable appliance, it takes lonyer to wear out the existing stock. Therefore, the speed of adjustment is lower. Over the sample period, more durable electric appliances such as those for heating and cooling have penetrated the market. Thus the stock of electric appliances has become more durable as time goes on. The estimated lag coefficient would therefore have a higher and higher magnitude in later sample periods.

\section{Own-Price Elasticities}

Figure 2 shows the trends of the estimated short-run and long-run elasticities. ${ }^{3}$ The absolute values of both price elasticities decline substantially over time. The changes in these elasticity estimates are, indeed, very dramatic. For the first run with sample for 1055-64, the estimated short-run and long-run price elasticities are, -0.801 and -1.360 , respectively. The corresponding estimates from the last regression for 1969-78 are on $1 y-0.133$ and -0.498 , respectively. Note that the estimated price elasticities remain fairly stable for the last three runs where the price elasticities seem to reach a lnwer hnund.

The results presented here are in sharp departure from the usual expectation that electricity consumers should have become more price conscious (and thus exhibit higher price responsiveness) during the recent upturns in electricity prices. The results show, however, that price elasticities in absolute value are smaller when more recent data are included in the sample. 


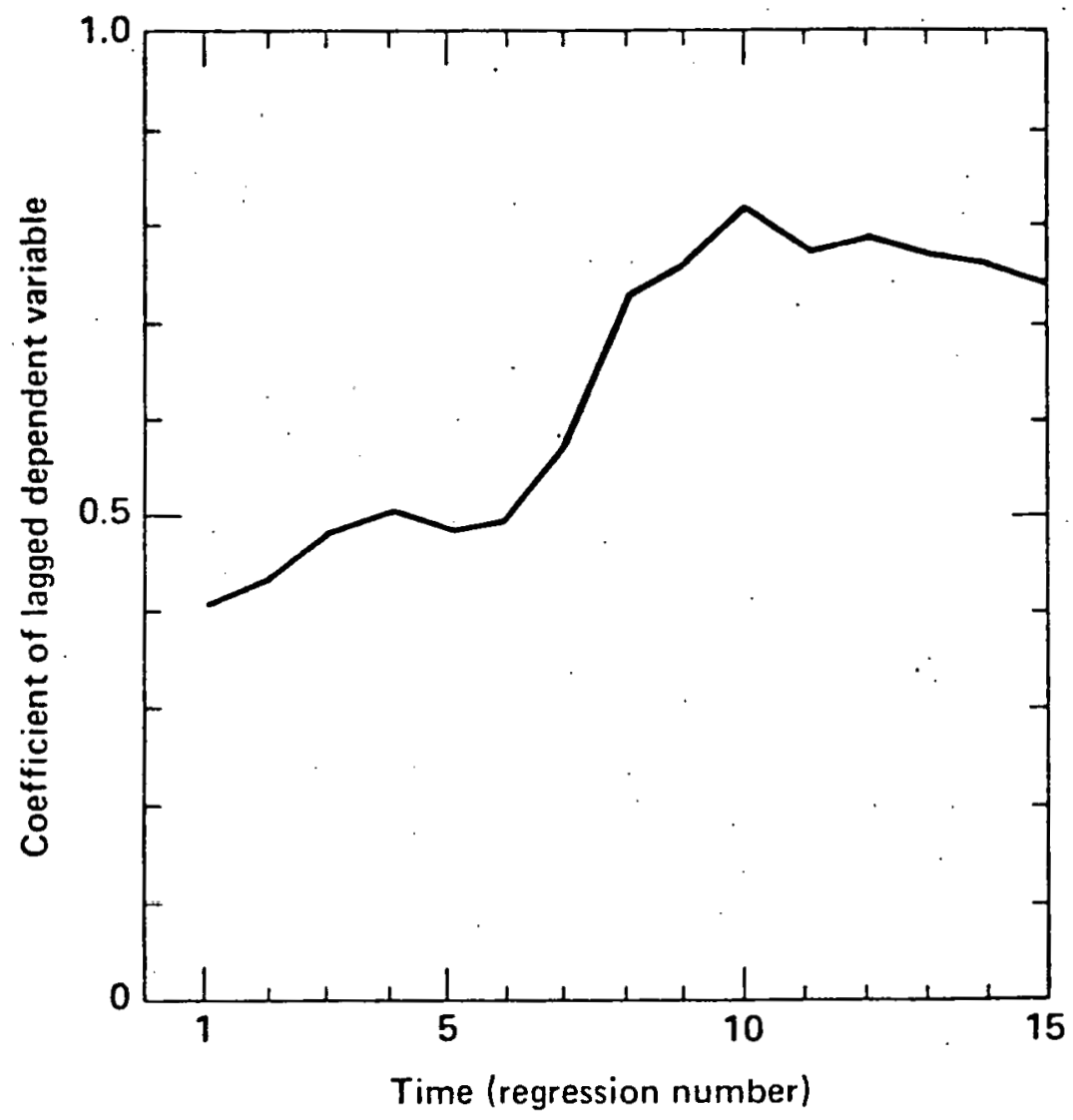

Figure 1. Estimated Coefficients of the Lagged Dependent Variable 


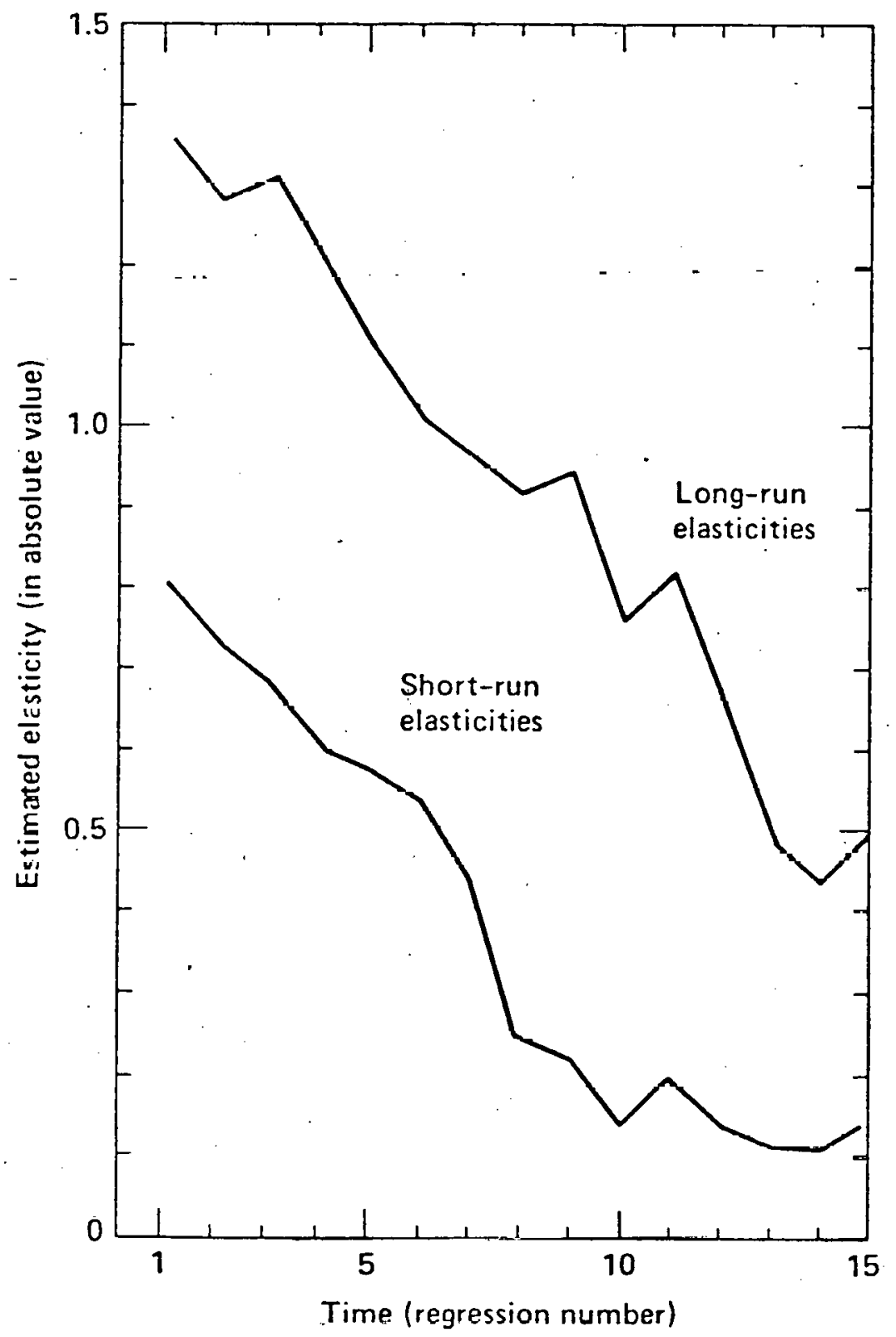

Figure 2. Estimated Short-Run and Long-Run Own Price Elasticities in Absolute Value 
Since the pattern of these changes appears to be gradual and smooth over time, the causes are unlikely to result from such sudden shocks as the oil embargo or the reversal of the decreasing trend of electricity prices, although impacts of these events will be investigated separately later.

A probable explanation for the downward trend in price elasticities lies in the pattern of electric end-uses, that is in the stock of electric appliances. The early sample periods cover a time during which the stocks of intensive electricity-using appliances were rapidly accumulated. Table 3 shows the saturation levels (percentage of total occupied housing units having one or more of the electric appliances under each end-use category) of major end-uses for 1960, 1970, and 1978. In 1960, only a small fraction of houses had electric appliances for such intensive electricity usage as air conditioning, heating and clothes drying. By 1970, such heavy electricity uses had gained substantial market shares. However, after 1970, the rate of increases in these end-uses slowed considerably. For example, in the case of electric heating, the saturation level increased more than $300 \%$ between 1960 to 1970; But it increased only about $100 \%$ from 1970 to $1978 .^{4}$ In the case of air conditioning, the saturation level increased by $200 \%$ from 1960 to 1970 ; this rate of increase reduced to only $40 \%$ between 1970 to 1978.

During 1950's and 1960's, the stocks of major electric appliances were being rapidly accumulated by both existing and new residential customers. Responses to price changes were therefore much greater before than after 1970 when the rate of accumulation of electric appliances slowed down substantially. After most families have purchased needed major electric appliances, aggregate adjustment to any price changes are limited only to replacement. and new cust.nmers.

\section{Customer Coefficient}

Figure 3 shows the estimated short-run and long-run elasticities with respect to the number of residential customers. Both elasticity estimates decline over time. The estimated short-run elasticity is 0.825 for the first run, and decreases rapidly reaching a minimum at Run 12, then remaining quite constant at around 0.22. The estimated long-run customer elasticity remains above unity for the first 11 runs and then decreases to a value slightly lower than unity $(0.91-0.98)$. The unusually high estimate of 1.8 from the tenth run (1964-73) is unexpected and cannot be reasonably explained. 
Table 3. Saturation Levels of Electricity End-Uses

\begin{tabular}{|c|c|c|c|}
\hline \multirow{2}{*}{ End-Use } & \multicolumn{3}{|c|}{$\begin{array}{c}\text { Saturation Leve } 1 \\
(\%)\end{array}$} \\
\hline & 1960 & 1970 & 1978 \\
\hline Refrigeration & a & 98.70 & 99.20 \\
\hline Lig̣hting & 100.00 & 100.00 & 100.00 \\
\hline Electric Water lleating & 20.37 & 25.38 & 31.50 \\
\hline Air Conditioning & 12.42 & 38.15 & 53.5 \\
\hline Electric Heating & 1.76 & 7.69 & 15.9 \\
\hline Electric Cooking & 30.84 & 40.61 & 50.3 \\
\hline Home food freezing & 18.40 & 28.22 & \\
\hline F.lertrie rloth drying & 11.90 & 11.73 & \\
\hline Electric cloth washing & 73.66 & 71.11 & \\
\hline T.V. & 87.30 & 95.50 & \\
\hline Radio & 91.48 & & \\
\hline Dishwasher & & 18.86 & \\
\hline & & & \\
\hline
\end{tabular}

a. Blanks indicate no data available. Source: U.S. Bureau of the Census [10]. 


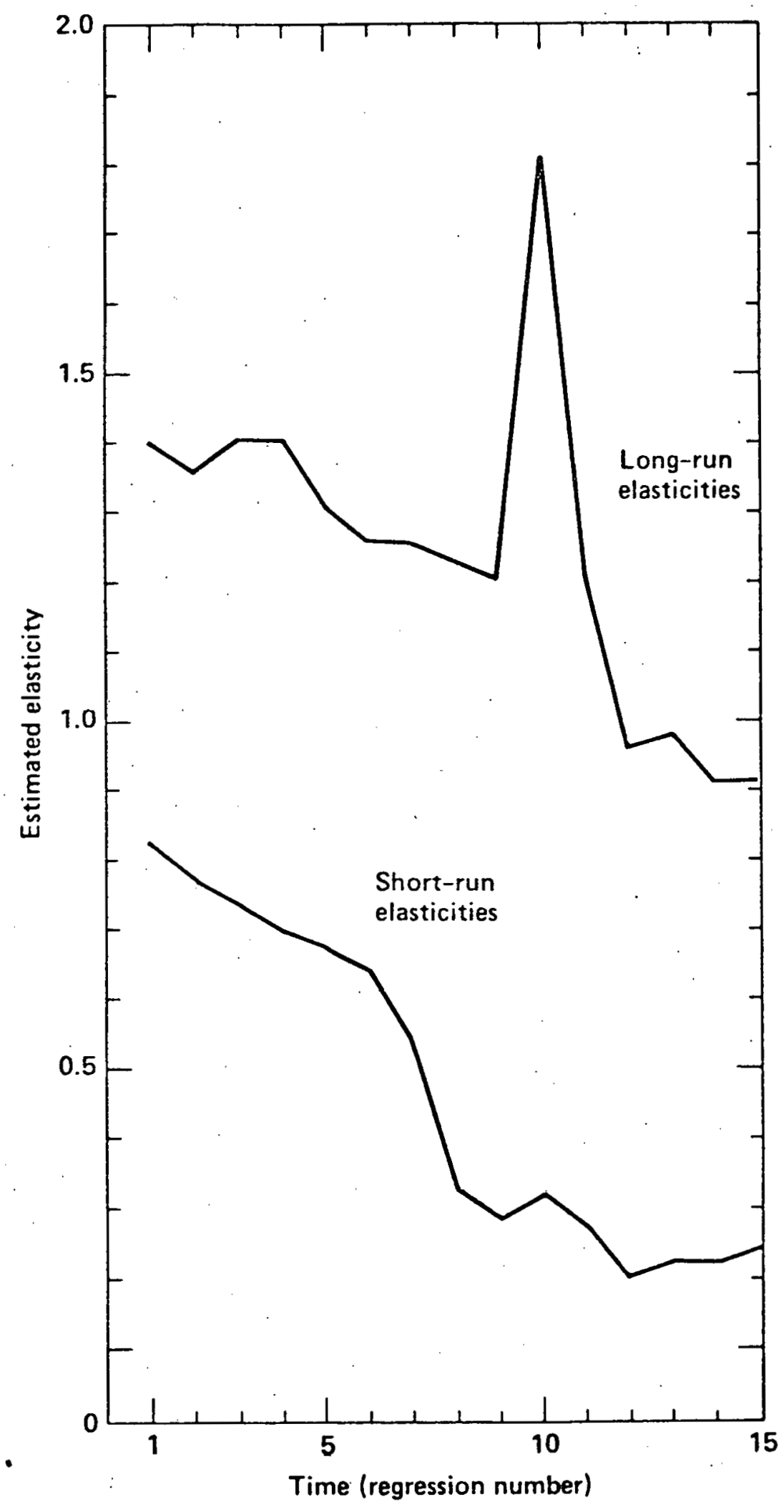

Figure 3. Estimated Short-Run and Long-Run Elasticities of Residential Customers 
The customer elasticites measure the effects on demand due to additions of new customers. Throughout the sample period, the number of residential customers was always increasing (at about $2 \%$ per year). The results in Table 1 and Figure 3 show that in the estimated short-run elasticity is always below unity indicating that new customers always have smaller average electricity consumption.than existing customers.

The higher short-run elasticities in earlier sample periods indicate that the differences in the stock of appliances between existing and new customers are much less in earlier years than in later years. In early years, the major end-use appliances were either necessity items such as lighting, cooking, refrigeration and clothes washing, or less electricity intensive items such as TV and radio. In more recent years, the increasing use of such items as electric heating and air conditioning make the differences in usage much more uranticic.

Once established, existing customers continue to purchase new electricity-using durables. This effect is captured by the long-run elasticity which is estimated at well-above unity for earlier sample periods, declining to somewhat below unity for the most recent periods. These results imply that for earlier years new customers became larger users of electricity than existing customers in the long-run, while for recent years new customers would in the long-run demand the same amount of electricity as present users. In other words, for the later case, long-run growth in total residential demand is directly proportional to growth in the number of customers which is a reasonable equilibrium expectation.

The results presented here are in contradiction with the hypothesis that the impacts of new customers shouldbe total and immediate. In such a situation, the short-run and long-run elasticities should all he equal to unity. Based on this hypothesis, one would specify per customer demand rather than total demand as the endogeneous variable in Equation (1). This specification assumes that new and existing customers all have the same pattern of electricity use (or, more precisely, the same stock of appliances), a very restrictive assumption. We have estimated such a model with the same moving regression as those presented in Table 1. Results show that the pattern of changes in the important parameter estimates such as lagged demand, 
price, and income coefficients is very erratic for the runs involving data from the 1950's to $1960^{\prime} \mathrm{s}$. For example, using the per-customer demand as the dependent variable, the estimated coefficient on lagged demand is extremely low (less than 0.1) and is generally statistically insignificant. For runs including data from the 1970 's, the estimated coefficients for all structural variables are fairly similar between the two model specifications. The instability of the estimated parameters from the restrictive assumption of proportionality indicates misspecification of the model. The results obtained from this analysis, therefore, argue for a specification with total demand rather then per-customer demand (or so called normalized demand).

\section{FALLING VS RISING ELECTRICITY PRICES}

It is often speculated that electricity demand elasticities during a period of rising prices are different from those in a period of falling prices. National average current prices fell monotonically from 1955 to 1969 and then increased monotonically after 1969. In real terms, prices fell consistently from 1955 to 1971, increased in 1972, declined again in 1973, and then kept increasing through 1978. If there were a structural change due to the reversal of the declining trend of electricity prices, it would have occurred sometime during 1969-1972.

In order to test the hypothesis of structural change due to the reversal of the trend of electricity prices, the sample was partitioned into two periods using each of five years from 1968 through 1972 as an alternative breaking point. These regression results are not presented here. Again the F-statistic is calculated for each pair of regression equations.

These results reveal several interesting findings. The computed F-statistics indicate that the demand equations estimated from the two separated samples are all significantly different at the 0.01 significance level. Therefore, the hypothesis of no structural change $\left(H_{0}\right)$ is rejected in all cases. However, there is an apparent decreasing trend of the values of the computed F-statistic. When the breaking point moves to a later year, the difference between the two sets of regression estimates becomes less significant. The declining trend in statistical significance appears to be more closely related to the evolution of the stock of appliances than to the changing pattern of electricity prices. 
In order to detect the timing of structural changes, Quandt [8] suggested a test by computing the log likelihood for different partitions of the sample. The Quandt test amounts to computing the weighted sum of the two residual sums of squares for each pair of regressions.

For the Quandt test, we compare these sums and choose the one with the minimum value which is for the partition (1955-68 vs 1969-78). These results would have supported a conclusion that a structural change due to the reversal of the falling trend of electricity prices occurred in 1969. However, real electricity prices decreased consistently until 1972 while the current electricity prices did not reverse its declining trend until 1970. Therefore, a structural change as a result of reversing the decline in electricity prices in 1969 would occur too early either for real or current prices. Thus, there is stronger evidence of structural changes in the moving regression analysis than those revealed in the analysis of falling vs rising prices.

\section{IMPACT OF THE OIL EMBARGO}

In order to investigate whether or not there was a structural change due to the oil embargo in 1973, the sample is partitioned into two periods, 1955-1973 and 1974-1978. The regression results are not presented here. The same test for a change in demand structure is performed here as in the previous section. Not only is the F-statistic smaller in magnitude than those computed in the previous section, it is clearly a extension of the declining trend of the calculated $F$-values from the previous analysis. The conclusion seems obvious. Despite the fact that the F-test suggests a significant structural difference between the two sets of regression results, the assertation that this was due to the oil embargo is even weaker statistically than the previous hypothesis that the reversal of the declining trend of electricity prices caused a structural demand change.

\section{CONCLUSIUN}

A moving regression method was employed to investigate changes in residential electricity demand over time. The statistical results show a strikingly consistent pattern of change for most of the structural variables. 
The most important finding of this study is that the estimated structure of residential electricity demand changes systematically over time as a result of changes in the characteristics (both durability and saturation level) of the stock of appliances. Furthermore, there is not strong evidence that the structural changes in demand occurred due to either the reversal of the declining trend of electricity prices or the impact of the 1973 oil embargo.

\section{FOOTNOTES}

1. See Maddala [9] for a review of some of these models.

2. For computing the F-statistic in this analysis, $T$ refers to the number of observations which is 960 (20 years and 48 states).

3. Long-run price elasticity (LE) is calculated as $L E=\beta_{2} /\left(1-\beta_{1}\right)$ where is the estimated short-run price elasticity and $B_{1}$ is the estimated lag coefficient in Equation (1).

4. The saturation level of electric heating is relatively lower than other end-uses. However, as shown by Hirst et al [7], electric heating accounted for $16 \%$ of total residential electricity use in 1977.

\section{REFERENCES}

1. Barnes, Roberta, Robert Grillingham and Robert Hagemann, "The Short-Run Residential Demand for Electricity", Review of Economics and Statistics, Vol. 63, No. 4, November 1981, pp. 541-551.

2. Bohi, Douglas R., Analyzing Demand Behavior, A Study of Energy Elasticities, The Johns Hopkins University Press, 1982

3. Brown, R. L., J. Ourbin, and J. M. Evans, "Techniques for Testing the Constancy of Regression Relationships Over Time", Journal of The Royal Statistical Society, Series B, Vol. 37, 1975, pp. 149-163. 
4. Chern, Wen S. and Richard E. Just, "Regional Analysis of Electricity Demand Growth", Energy, Volume 5, No. 1, 1980, pp. 35-46.

5. Chern, W. S. et a1., The ORNAL State-Level Electricity Demand Forecasting Model, Oak Ridge National Laboratory Report, ORNL/NUREG-63, July 1980.

6. Chern. W. S., R. E. Just, and H. S. Chang, A Varying Elasticity Model of Electricity Demand With Given Appliance Saturation, Oak Ridge National Laboratory Report, ORNL/NUREG/TM-438, June 1982.

7. H1rst, Eric. "Review of Data Related to Energy Use in Residential and Commercial Buildings", Management Science, Vol. 26. No. 9, September 1980, pp. 857-870.

8. Quandt, R. E., "The Estimation of a Linear Regression System Obeying Two Separate Regimes," Journal of the American Statistical Association, 1958, pp. 873-880.

9. Maddala, G. S., Econometrics, McGraw-Hill Book Co., 1977.

10. U.S. Bureau of the Census, 1960 Census of Housing: Detailed Housing Characteristics, U.S. Summary, July 1972; 1970 Census of Housing:

Detailed Housing Characteristics, U.S. Summary, July 1972; Annual Housing Survey: 1978, Part F. Energy-Related Housing Characteristics, August 1981; U.S. Government Printing Office, Washington, D.C.

11. Taylor, Lester, "The Demand for Electricity: A Survey", The Bell Journal of Economics, Vol. 6, Spring, 1975, pp. 74-110. 


\section{ACKNOWLEOGMENTS}

Work performed under the auspices of the U.S. Department of Energy by the Lawrence Livermoré National Laboratory under contract number W-7405-ENG-48. Most of the regression analysis was done when Howarth Bouis was associated with the Electric Power Research Institute. A partial support from EPRI to complete this study is acknowledged.

DISCIAIMER

This document was prepared as an account of work sponsored by an agency of the Inited States Covermuent. Neither the linited Slates Government nor the I Iniversity of California nor any of their employees, makes any warranty, express or implied, or assumes any legal liability or responsibility for the accuracy, completeness, or usefulness of any information, apparatus, product, or process disclosed, or represents that its use would not infringe privately owned rights. Reference herein to any speclflc conmurucial pu uducts, process, or hervice by trade name, trademark, manufacturer, or otherwise, does not necessarily constitute or imply its endorsement, recommendation, or favoring by the Inited States Covernment or the University of California. The view's and opinions of authors expressed herein do not necessarily state or reflect those of the 4 !nited States Government thereof, and shall not be used for advertising or product endorsement purposes. 


$$
1
$$

